\title{
FAMÍLIAS MONOPARENTAIS, VULNERABILIDADE SOCIAL E CUIDADO
}

\author{
SINGLE-PARENT FAMILIES, SOCIAL VULNERABILITY \\ AND CARE
}

Thamis Dalsenter Viveiros de Castro

Doutora em Direito Civil pela Universidade do Estado do Rio de Janeiro - UERJ. Mestre em Direito Constitucional e Teoria do Estado pela PUC-Rio. Professora de Direito Civil da Pontifícia Universidade Católica do Rio de Janeiro - PUC-Rio. Coordenadora do grupo de pesquisas "Direitos da gestante e violência obstétrica" e do curso de extensão "Aspectos jurídicos da violência obstétrica", ambos na PUC-Rio.

Vitor Almeida

Doutor e Mestre em Direito Civil pela Universidade do Estado do Rio de Janeiro (UERJ). Discente do Estágio Pós-Doutoral do Programa de Pós-Graduação em Direito da Universidade do Estado do Rio de Janeiro (PPGD-UERJ). Professor Adjunto de Direito Civil da Universidade Federal Rural do Rio de Janeiro (ITR/UFRRJ). Professor de Direito Civil da PUC-Rio. Professor convidado do Ceped-UERJ e Esap-PGE. Advogado.

Resumo: O presente artigo tem como objetivo analisar os principais contornos da família monoparental na experiência brasileira, bem como os impactos da pandemia do coronavírus na esfera do cuidado e da vulnerabilidade que atingem tais arranjos de forma mais drástica. Ao lado de tal exame, percorrese, diante do silêncio legal sobre tais entidades familiares, os possíveis caminhos para uma disciplina jurídica de promoção da dignidade de seus membros.

Palavras-chave: Família monoparental. Pandemia. Cuidado. Vulnerabilidade.

Abstract: This article aims to analyze the main outlines of the single-parent family in the Brazilian experience, as well as the impacts of the coronavirus pandemic in the sphere of care and vulnerability that affect such arrangements more drastically. Along with such an examination, in view of the legal silence over such family entities, the possible paths for a legal discipline to promote the dignity of its members are explored.

Keywords: Single-parent family. Pandemic. Caution. Vulnerability.

Sumário: Introdução - 1 A monoparentalidade na experiência brasileira e sua invisibilidade jurídica 2 Cuidado e vulnerabilidade nas relações familiares - $\mathbf{3}$ Os impactos da pandemia e a ausência de tutela efetiva para as famílias monoparentais - Considerações finais 


\section{Introdução}

“Troco uma máscara por um alimento". ${ }^{1}$ Esses eram os dizeres do cartaz que uma menina negra de nove anos segurava em um sinal de trânsito em 13.5.2020, no cruzamento de uma das mais movimentadas avenidas do bairro do Recreio dos Bandeirantes, na zona oeste do Rio de Janeiro. A foto com a imagem da criança viralizou na internet durante a pandemia do Covid-19, e se tornou símbolo da invisibilidade das famílias monoparentais no Brasil, descortinando o cruel desamparo e a vulnerabilidade social que atingem tais entidades familiares em tempos pandêmicos, especialmente na dimensão econômica. O que poderia ser mais um exemplo dramático dos nefastos efeitos econômicos sofridos por milhões de pessoas em razão do coronavírus e das necessárias medidas sanitárias de isolamento social e fechamento de diversos setores ligados ao comércio, é, na verdade, o retrato do drama social que atinge diversas famílias monoparentais brasileiras independentemente da pandemia, em virtude da estrutura que identifica tal arranjo e que onera somente um ascendente no cuidado, criação e sustento integral dos seus filhos.

Desse modo, a vulnerabilidade social atinge mais fortemente as formações familiares monoparentais em razão do acúmulo concentrado dos trabalhos domésticos e dos cuidados com os filhos e atividades profissionais em somente uma figura, o que exige um exercício da responsabilidade parental de forma isolada e exclusiva. Esse cenário de desigualdades é negligenciado pelo ordenamento jurídico, que não disciplina as peculiaridades e demandas dessa entidade familiar tão comum na formação social brasileira.

Depois da divulgação da emblemática foto na internet, houve um intenso movimento de busca pela história por trás da imagem, o que implicou diversos atos de solidariedade e permitiu conhecer a realidade da vida da menina de nove anos. A mãe trabalhava como vendedora de picolé e diarista até o início da pandemia, quando ficou sem trabalho em razão das restrições à circulação de pessoas e foi levada a vender doces no sinal para sobreviver e prover alimentos para os seus quatro filhos, eis que cuida e cria sozinha toda sua prole. No início, a mãe relatou que, apesar de ter ficado "envergonhada" e com medo das críticas das pessoas quando passou a ser procurada por jornalistas interessados na história, todas as doações recebidas após a divulgação da foto foram fundamentais para sua família. ${ }^{2}$

\footnotetext{
IMAGEM de menina trocando máscara por comida viraliza no Rio e gera onda de solidariedade. G1, 13 maio 2020. Disponivel em: https://g1.globo.com/rj/rio-de-janeiro/noticia/2020/05/13/imagem-de-menina-tro cando-mascara-por-comida-viraliza-no-rio-gera-onda-de-solidariedade.ghtml. Acesso em: 1ํ jun. 2020.

2 IMAGEM de menina trocando máscara por comida viraliza no Rio e gera onda de solidariedade. G1, 13 maio 2020. Disponível em: https://g1.globo.com/rj/rio-de-janeiro/noticia/2020/05/13/imagem-de-menina-tro cando-mascara-por-comida-viraliza-no-rio-gera-onda-de-solidariedade.ghtml. Acesso em: 1ํjun. 2020.
} 
Essa emocionante história ilustra a gravíssima desigualdade social brasileira e evidencia o alto grau de vulnerabilidade experimentado especialmente pelas famílias monoparentais no contexto da pandemia. No Brasil dessa e de tantas outras famílias que sentem fome, os cuidados básicos de saúde são privilégios de poucos, inacessíveis para grande parte da população. De fato, enquanto muitos brasileiros se presenvam com o uso de máscaras e álcool em gel para evitar o contágio do coronavírus e podem respeitar as diretrizes de distanciamento social recomendadas pelas autoridades sanitárias, a menina e seu cartaz denunciam o abismo social que priva de alimentos e saúde muitas famílias, especialmente as monoparentais.

De fato, não é de hoje que os rendimentos e a variação patrimonial entre as famílias nucleares e as monoparentais apresentam significativa diferença, e a ausência de políticas públicas e o efetivo reconhecimento agravam ainda mais a vulnerabilidade social desses grupos familiares. No contexto da pandemia, essa entidade familiar, tradicionalmente referenciada na figura feminina, demanda tutela jurídica ampliada, de modo a reforçar a proteção conferida aos vulneráveis para garantir o respeito à dignidade da pessoa humana em sua perspectiva existencial e patrimonial. Nessa linha, o presente trabalho almeja analisar os principais contornos da família monoparental na experiência brasileira, bem como os impactos da pandemia do coronavírus na esfera do cuidado e da vulnerabilidade que atingem tais arranjos de forma mais drástica. A par de tal exame, percorre-se, diante do silêncio legal sobre tais entidades familiares, os possíveis caminhos para uma disciplina jurídica de promoção da dignidade de seus membros.

\section{A monoparentalidade na experiência brasileira e sua invisibilidade jurídica}

No campo da teoria civilista brasileira, o direito das famílias é o ramo que mais se modificou ao longo das últimas décadas. Especialmente a partir da promulgação da Constituição Federal de 1988, a tutela jurídica das relações familiares passou a ser centrada na ideia de família democrática, na qual, como explica Maria Celina Bodin de Moraes:

não há direitos sem responsabilidades, nem autoridade sem democracia. A democratização no contexto da família implica alguns pressupostos específicos, tais como a igualdade, o respeito mútuo, a autonomia, a tomada de decisões através da comunicação, o resguardo da violência e a integração social. ${ }^{3}$

MORAES, Maria Celina Bodin de. A nova família, de novo. Estruturas e funções das famílias contemporâneas. Revista Pensar (UNIFOR), Fortaleza, v. 18, n. 2, p. 587-628, maio/ago. 2013. p. 592. 
O reconhecimento jurídico de diversos tipos de arranjos familiares, ${ }^{4}$ que se formam da livre escolha de seus membros, foi certamente uma das mais impactantes transformações do direito das famílias. Ao assumir essa premissa democrática que sustenta a noção de pluralismo familiar, a tutela da família passou a ser centrada nas demandas existenciais de seus membros, que podem, nesse ambiente de renovada liberdade, formar o tipo de família mais adequado aos afetos, e não apenas aos bens envolvidos.

Mesmo diante da multiplicidade de modelos familiares, ${ }^{5}$ todos os arranjos que compõem a noção de família têm como traço comum a incorporação do respeito aos direitos fundamentais de seus membros, razão pela qual, a despeito dessa pluralidade, é possível agrupá-los sob a denominação "famílias democráticas". ${ }^{\circ}$ Em suma, "famílias democratizadas nada mais são do que famílias em que a dignidade de cada membro é respeitada e tutelada". ${ }^{7}$ Como resultado desse processo de democratização da tutela das famílias, que tem a dignidade de seus membros como centro da proteção de interesses, é fundamental pressupor uma tutela ainda mais intensa dos direitos dos vulneráveis no contexto das relações familiares.

$\mathrm{Na}$ experiência brasileira, segundo dados do IBGE, as entidades familiares têm se diversificado cada vez mais e o número de arranjos não tradicionais como as uniões estáveis, e, com o aumento das separações e divórcios, as famílias reconstituídas, nas quais os filhos podem ser apenas de um dos cônjuges ou companheiros, tem crescido significativamente. 0 aumento das famílias monoparentais também é identificado nas estatísticas, em especial em razão das separações e

4 Como elucida Luiz Paulo Lôbo, os “tipos de entidades familiares explicitados nos parágrafos do art. 226 da Constituição são meramente exemplificativos, sem embargo de serem os mais comuns, por isso mesmo merecendo referência expressa. As demais entidades familiares são tipos implícitos incluídos no âmbito de abrangência do conceito amplo e indeterminado de família indicado no caput. Como todo conceito indeterminado, depende de concretização dos tipos, na experiência da vida, conduzindo à tipicidade aberta dotada de ductilidade e adaptabilidade" (LOBO, Paulo Luiz Netto. Entidades familiares constitucionalizadas. In: CONGRESSO BRASILEIRO DE DIREITO DE FAMÍLIA, III. Anais... Belo Horizonte: [s.n.], 2002. p. 95).

5 Sobre o tema da pluralidade e da função da família, esclarece Rose Melo Vencelau Meireles: “De fato, o termo família é utilizado pelo constituinte de forma ampla, devendo a função do instituto ser seu elemento unificador. Ora, se a função da família se realiza quando através da comunhão de vida se permita o desenvolvimento de cada uma das pessoas que a integram, sempre que assim for configurada a convivência, deve receber proteção do Estado como família. Em outras palavras, afirmar que esta ou aquela forma de convivência constitui entidade familiar significa dizer que como tal, como família, é merecedora de especial proteção do Estado, nos termos do caput do art. 226 da Constituição Federal" (MEIRELES, Rose Melo Vencelau. Em busca da nova família: uma família sem modelo. Civilistica.com, Rio de Janeiro, ano 1, n. 1, jul./set. 2012. Disponível em: http://civilistica.com/embusca-da-nova-familia/. Acesso em: 15 out. 2014).

6 Termo e a sua utilização deste modo foram apresentados por MORAES, Maria Celina Bodin de. A nova família, de novo. Estruturas e funções das famílias contemporâneas. Revista Pensar (UNIFOR), Fortaleza, v. 18, n. 2, p. 587-628, maio/ago. 2013. p. 592.

7 Termo e a sua utilização deste modo foram apresentados por MORAES, Maria Celina Bodin de. A nova família, de novo. Estruturas e funções das famílias contemporâneas. Revista Pensar (UNIFOR), Fortaleza, v. 18, n. 2, p. 587-628, maio/ago. 2013. p. 592. 
divórcios. ${ }^{8}$ Os dados estatísticos sobre os arranjos familiares são ferramentas fundamentais para demonstrar o comportamento das famílias, mas especialmente para a formulação e direcionamento das políticas públicas.

O IBGE classifica os tipos de composição familiar monoparental em mulher sem cônjuge com filho(s), mulher sem cônjuge com filhos(s) e com parente(s), homem sem cônjuge com filho(s), homem sem cônjuge com filho(s) e parente(s) e outros. O panorama estatístico apontava há dez anos um aumento de "1 ponto percentual a ocorrência de famílias monoparentais femininas (com ou sem parentes), de $15,3 \%$ para $16,2 \%$, enquanto as masculinas (com ou sem parentes) se mantiveram nos mesmos patamares, 1,9\% para 2,4\%". Igualmente se observou um "percentual consideravelmente inferior de famílias monoparentais femininas com ou sem parentes nas áreas rurais, 9,1\% contra 17,4\% nas áreas urbanas". Outro dado relevante apontado pelo censo demográfico e que atinge, em especial, as famílias monoparentais femininas, são as chamadas, para fins do levantamento, de famílias conviventes, ou seja, quando há a presença de diversos núcleos familiares em uma mesma unidade doméstica. Registra-se que o "tipo mais frequente dentre as famílias conviventes é aquele formado pelas monoparentais femininas $(53,5 \%)$ ", que foram "provavelmente compostas por filhas dos responsáveis e/ou dos cônjuges, que tiveram seus filhos sem contrair matrimônio ou retornaram à casa dos pais por motivo de separação ou divórcio". ${ }^{9}$ Tais dados comprovam que as famílias monoparentais são, em sua feição, femininas, urbanas e a maioria entre as famílias conviventes.

Embora a ideia de vulnerabilidade esteja presente em diversos tipos de formação familiar, é preciso destacar que a família monoparental é um modelo particularmente sensível e demandante da tutela reforçada dirigida aos vulneráveis. Constituídas, como se vê no levantamento estatístico acima, a partir de um núcleo referencial essencialmente feminino, as famílias monoparentais são especialmente expostas às desigualdades e às opressões que conformam as relações de gênero no Brasil em seus variados âmbitos. ${ }^{10}$

8 BRASIL. Ministério do Planejamento, Orçamento e Gestão. Instituto Brasileiro de Geografia e Estatística. Censo Demográfico - 2010. Famílias e domicílios. Resultados da amostra. Rio de Janeiro: IBGE, 2010. Disponível em: https://biblioteca.ibge.gov.br/visualizacao/periodicos/97/cd_2010_familias_domicilios_ amostra.pdf. Acesso em: 3 jun. 2020. Cabe frisar que o Censo Demográfico de 2020, em função das orientações do Ministério da Saúde relacionadas ao quadro de emergência de saúde pública causado pelo Covid-19, foi adiado para o ano de 2021.

9 BRASIL. Ministério do Planejamento, Orçamento e Gestão. Instituto Brasileiro de Geografia e Estatística. Censo Demográfico - 2010. Famílias e domicílios. Resultados da amostra. Rio de Janeiro: IBGE, 2010. Disponivel em: https://biblioteca.ibge.gov.br/visualizacao/periodicos/97/cd_2010_familias_domicilios_ amostra.pdf. Acesso em: 3 jun. 2020.

10 Sobre esse ponto é preciso destacar que a desigualdade de gênero pode se fazer presente em qualquer tipo de arranjo familiar. Como se verifica no levantamento Outras formas de trabalho, feito pelo IBGE, as 
Mas não é somente no recorte de gênero que as famílias monoparentais apresentam traço distintivo na distribuição da responsabilidade parental. Segundo dados do levantamento feito pelo IBGE sobre as Desigualdades sociais por cor ou raça no Brasil, o adensamento domiciliar excessivo - situação em que há mais de três moradores por cômodo utilizado como dormitório no domicílio - e o ônus excessivo de aluguel - situação em que o valor do aluguel iguala ou ultrapassa $30 \%$ do rendimento familiar - são maiores entre as pessoas pretas ou pardas e ocorrem com muito mais frequência em arranjos familiares formados por mulheres sem cônjuge e com filho(s) até 14 anos, em que se integrar a população preta ou parda o adensamento excessivo chega a $11,9 \%$ e o aluguel excessivo, a 13,6\%. ${ }^{11}$ 0 estudo ainda demonstra que a presença de bens permanentes relacionados a tarefas domésticas apresenta relevante clivagem segundo a cor ou a raça: "em $2018,44,8 \%$ da população preta ou parda residia em domicílios sem máquina de lavar, proporção esta superior ao dobro da verificada na população branca $(21,0 \%)$ ". Tais dados evidenciam que "a população preta ou parda, em especial as mulheres, tem maior carga de trabalho doméstico, como a lavagem de roupa, entre outros trabalhos não remunerados". ${ }^{12}$

O panorama estatístico revela uma invisibilidade das formações familiares monoparentais na realidade brasileira que se origina do seu próprio perfil demográfico, eis que em sua maioria são mulheres negras que chefiam sozinhas os lares e cuidam dos seus filhos, sem auxílio dos pais nesta árdua tarefa. No período da pandemia, dados do Instituto Locomotivas demonstram que o Brasil tem 11 milhões de mães-solo, sendo que 57\% (cinquenta e sete por cento) vivem abaixo da linha da pobreza. São mulheres que não podem contar com a presença ou o auxílio dos pais para criarem seus filhos. Muitas são abandonadas durante a gestação ou logo após o nascimento dos seus filhos. O levantamento ainda indica que "em $31 \%$ das casas sustentadas por elas, já faltou dinheiro para comprar produtos de limpeza com a pandemia e em $35 \%$ faltou comida". ${ }^{13}$

mulheres dedicaram quase o dobro de horas semanais $(21,4)$ aos afazeres domésticos ou ao cuidado de pessoas, especialmente crianças, em relação aos homens (11 horas semanais) (BRASIL. Ministério do Planejamento, Orçamento e Gestão. Instituto Brasileiro de Geografia e Estatística. Pesquisa Nacional por Amostra de Domicílios Contínua - PNAD Contínua. Disponível em: https://www.ibge.gov.br/estatisticas/ sociais/populacao/17270-pnad-continua.html?edicao=27762\&t=sobre. Acesso em: 22 jun. 2020).

11 BRASIL. Instituto Brasileiro de Geografia e Estatística. Desigualdades sociais por cor ou raça no Brasil. Estudos e Pesquisas. Informação Demográfica e Socioeconômica, Rio de Janeiro, n. 41, p. 1-12, 2019. Disponível em: https://biblioteca.ibge.gov.br/visualizacao/livros/liv101681_informativo.pdf. Acesso em: 3 jun. 2020.

12 BRASIL. Instituto Brasileiro de Geografia e Estatística. Desigualdades sociais por cor ou raça no Brasil. Estudos e Pesquisas. Informação Demográfica e Socioeconômica, Rio de Janeiro, n. 41, p. 1-12, 2019. Disponível em: https://biblioteca.ibge.gov.br/visualizacao/livros/liv101681_informativo.pdf. Acesso em: 3 jun. 2020.

13 DIA das Mães: a vida das 11 milhões de brasileiras que criam os filhos sozinhas. Fantástico, 10 maio 2020. Disponivel em: https://g1.globo.com/fantastico/noticia/2020/05/10/dia-das-maes-a-vida-das-11milhoes-de-brasileiras-que-criam-os-filhos-sozinhas.ghtml. Acesso em: 4 jun. 2020. 
Cabe assinalar que a Constituição da República de 1988, com base no princípio da pluralidade das entidades familiares, em seu art. 226, §4ํㅡ, prevê a comunidade formada pelos ascendentes e seus descendentes - as chamadas famílias monoparentais. De fato, essa forma de estrutura familiar sempre existiu no meio social. No entanto, além de não ter o reconhecimento jurídico e estatuto específico, este último inexistente até hoje, tal arranjo familiar sempre esteve reservado à imprevisibilidade dos acontecimentos da vida. E, mesmo após mais de duas décadas de seu reconhecimento em sede constitucional, a doutrina ainda é reticente em aceitar o planejamento destas entidades familiares. ${ }^{14}$ Ainda é bastante comum associar exclusivamente como causas da monoparentalidade os infortúnios da vida, como separações, divórcios, viuvezes, adoções unilaterais e celibatos. ${ }^{15}$

Como já dito, a doutrina recusava-se a admitir que, de forma consciente, autônoma e deliberada, as pessoas solteiras pudessem constituir a família monoparental por meio das técnicas de reprodução assistida e as chamadas "produções independentes", sob o argumento de que o dispositivo constitucional não teria por objetivo estimular a sua formação, mas tão somente reconhecê-las. ${ }^{16}$ Tal entendimento, contudo, foi arrefecido na medida em que os arranjos familiares se multiplicaram e a autonomia para fins de constituição da família foi promovida de forma democrática e como forma de atender às decisões autorreferentes existenciais das pessoas. O direito ao livre planejamento familiar, previsto no art. 226 , §7은 da Constituição, fundado na parentalidade responsável e na dignidade humana, compreende a autonomia reprodutiva, o que, por sua vez, não limita a formação das famílias monoparentais por meio das técnicas de reprodução assistida. ${ }^{17}$

14 Cf. ALMEIDA, Vitor. Planejando a família in vitro: o direito ao planejamento familiar e as famílias mono parentais. IBDFAM, 14 jun. 2013 Disponivel em: http://www.ibdfam.org.br/artigos/893/Planejando+a+ fam\%C3\%ADlia+in+vitro\%3A+o+direito+ao+palnejamento+familiar+e+as+fam\%C3ADlias+monoparentais. Acesso em: 21 maio 2020.

15 Aponta Demian Diniz da Costa que “de uma forma geral, alguns aspectos, ou melhor, algumas causas de monoparentalidade são encontradas em diversas sociedades, tornando-se comum entre diversos países, como, por exemplo, a viuvez, o celibato, o divórcio e a separação" (COSTA, Demian Diniz da. Famílias monoparentais: reconhecimento jurídico. Rio de Janeiro: Aide, 2002. p. 31).

16 Neste sentido, Eduardo de Oliveira Leite entende ser “precipitado e equivocado [invocar o] art. 226, parágrafo $4^{\circ}$ do texto constitucional como argumento legitimador da inseminação artificial da mulher solteira, separada ou divorciada", pois defende que "o dispositivo constitucional, de forma louvável, apenas inseriu na esfera da proteção estatal, as famílias 'monoparentais'; em momento algum as reconheceu com vistas a proliferação das mesmas" (LEITE, Eduardo de Oliveira. Procriações artificiais e o direito: aspectos médicos, religiosos, psicológicos, éticos e jurídicos. São Paulo: Revista dos Tribunais, 1995. p. 356). Registra, ainda, Guilherme Calmon Nogueira da Gama que “a Constituição não estimula a formação de famílias monoparentais, mas as reconhece" (GAMA, Guilherme Calmon Nogueira. A nova filiação: o biodireito e as relações parentais: o estabelecimento da parentalidade - filiação e os efeitos jurídicos da reprodução assistida heteróloga. Rio de Janeiro: Renovar, 2003. p. 359).

17 V., por todos, BARBOZA, Heloisa Helena. Reprodução humana como direito fundamental. In: DIREITO, Carlos Alberto Menezes; TRINDADE, Antônio Augusto Cançado; PEREIRA, Antônio Celso Alves (Org.). Novas perspectivas do direito internacional contemporâneo. Rio de Janeiro: Renovar, 2008; ALMEIDA, Vitor. 
Além disso, a partir da Resolução do Conselho Federal de Medicina no 2.013/2013, permitiu-se de forma expressa que pessoas solteiras, independentemente da orientação sexual, fossem pacientes das técnicas de reprodução assistida, o que foi seguido pelas resoluções posteriores, respectivamente, nํㅗ $2.121 / 2015$ e 2.168/2017, sendo esta última a que se encontra atualmente em vigor. Os dilemas éticos e jurídicos permanecem em face do suposto direito à biparentalidade, calcado no melhor interesse das crianças a nascerem, bem como o direito de conhecer a origem genética e o recurso à gestação de substituição, obrigatório no caso de homens solteiros e eventualmente presente no caso de muIheres solteiras. 0 tema escapa dos limites estreitos da análise da vulnerabilidade social no momento da pandemia e dos arranjos monoparentais, mas não impede a afirmação de que qualquer exame prévio e em abstrato do melhor interesse resulta inútil, bem como discriminatório com formações familiares não tradicionais. ${ }^{18}$

No entanto, há que se distinguir as experiências monoparentais fundadas no exercício da liberdade da mulher ou do homem, por meio da adoção ou reprodução assistida, por exemplo, das situações de monoparentalidade que não são fundadas em escolha legitima, mas impostas pelo abandono ou ausência, em geral, dos pais. Em geral, em razão da irresponsabilidade parental, o fenômeno das famílias monoparentais femininas resulta de uma não escolha da mulher e são os casos mais comuns na patriarcal e sexista sociedade brasileira, conforme amplamente indicados pelos dados estatísticos.

Em especial, a vulnerabilidade social é evidenciada nestes casos em que o ônus da gestação, do nascimento, da criação e do sustento dos filhos recai sobre a mulher, além das atividades domésticas e, não raras vezes, do cuidado com outros parentes idosos. Nessa perspectiva, as interseccionalidades ${ }^{19}$ são observadas

O direito ao planejamento familiar e as novas formas de parentalidade na legalidade constitucional. In: HIRONAKA, Giselda Maria Fernandes Novaes; SANTOS, Romualdo Baptista dos (Org.). Direito civil: estudos I Coletânea do XV Encontro dos Grupos de Pesquisa - IBDCIVIL. São Paulo: Blucher, 2018.

18 Cf. ALMEIDA, Vitor. Planejando a família in vitro: o direito ao planejamento familiar e as famílias monoparentais. IBDFAM, 14 jun. 2013 Disponivel em: http://www.ibdfam.org.br/artigos/893/Planejando+a+ fam\%C3\%ADlia+in+vitro\%3A+o+direito+ao+palnejamento+familiar+e+as+fam\%C3ADlias+monoparentais. Acesso em: 21 maio 2020.

19 “A discriminação interseccional é conceito que surgiu da percepção do fenômeno peculiar da discriminação sofrida por mulheres negras em contraste com a vivida por mulheres brancas, realidade para cuja análise não se presta a invocação abstrata da proibição de discriminação por sexo. Designada, no âmbito jurídico, sob o conceito amplo de discriminação múltipla, faz-se necessário distinguir, no interior do conceito jurídico, a perspectiva quantitativa (discriminação aditiva e composta, marcadas pela mera soma de critérios) da perspectiva qualitativa (discriminação interseccional). Nesse contexto, utilizase a expressão 'discriminação interseccional' para a compreensão da categoria jurídica da discriminação múltipla como fenômeno original, irredutível e inassimilável ao somatório de diversos critérios proibidos de discriminação de forma simultânea. A discriminação interseccional ocorre quando dois ou mais critérios proibidos interagem, sem que haja possibilidade de decomposição deles. Em seu conceito, é composta pelos elementos conceituais de intersecção de identidades consideradas como critérios proibidos de discriminação em 
nesses agrupamentos familiares dentro de um espectro maior de convivência em arranjos familiares maiores ou não. Condições socioeconômicas e aspectos ligados ao gênero e à raça foram o amálgama necessário para o agravamento das vulnerabilidades das famílias monoparentais e as múltiplas discriminações sofridas diariamente por seus integrantes. ${ }^{20}$

Apesar do expresso reconhecimento da família monoparental em sede constitucional, o Código Civil vigente, na linha do anterior, é completamente silencioso em relação à sua disciplina legal, bem como inexiste lei infraconstitucional específica que regulamente tal arranjo. Há quem defenda a desnecessidade de sua regulamentação ante a sua formação acidental e inexistência de eventual conflito entre os pais. No entanto, enquanto persiste a omissão do legislador infraconstitucional, o Poder Público não se vê obrigado a protegê-la, o que agrava a discriminação no meio social. Inegável que o silêncio na lei civil é ensurdecedor e menospreza as peculiaridades de tal arranjo familiar, que é especialmente atingido com a ausência de políticas públicas voltadas aos seus integrantes.

\section{Cuidado e vulnerabilidade nas relações familiares}

Na experiência constitucional brasileira, a dignidade da pessoa humana foi positivada como fundamento da República, diretamente vinculado ao objetivo primordial de erradicação da pobreza e da marginalização e de redução das desigualdades

estruturas de subordinação. Assim, a discriminação interseccional implica uma análise contextualizada, dinâmica e estrutural, a partir de mais de um critério proibido de discriminação. Por exemplo, uma mulher pertencente a uma determinada minoria está sujeita a estigmas e prejuízos diversos daqueles experimentados por homens pertencentes ao mesmo grupo. A discriminação baseada em mais de um critério deve ser vista, nessas situações, sob a perspectiva e considerando as experiências específicas do grupo subordinado, não de forma meramente quantitativa" (RIOS, Roger Raupp; SILVA, Rodrigo da. Democracia e direito da antidiscriminação: interseccionalidade e discriminação múltipla no direito brasileiro. Ciência e Cultura, ano 16, v. 69, n. 1, p. 44-49, 2017. p. 45. V. também AKOTIRENE, Carla. Interseccionalidade. São Paulo: Sueli Carneiro; Pólen, 2019).

20 “O estado da arte aponta para o predomínio da expressão 'discriminação múltipla' diante da discriminação motivada por mais de um critério proibido. [...] Discriminação múltipla é considerado, assim, um conceito 'guarda-chuva' dentro do cenário mundial de proteção dos direitos humanos. [...] Ao passo que a discriminação aditiva e a discriminação composta atrelam-se a uma perspectiva quantitativa (onde a discriminação em causa é considerada a soma de discriminações diversas), a discriminação interseccional vincula-se a uma perspectiva qualitativa (na qual o fenômeno discriminatório é percebido como uma nova e específica forma de discriminação, distinta da mera adição de critérios). [...] Nesse quadro, discriminação aditiva ocorre quando alguém é discriminado com base em diversos critérios proibidos de discriminação e em momentos diferentes. [...] Como na discriminação aditiva, a discriminação composta pressupõe o somatório de critérios proibidos de discriminação, num sentido quantitativo. 0 que distingue a discriminação composta da discriminação aditiva é a concomitância de fatores em uma mesma situação" (RIOS, Roger Raupp; SILVA, Rodrigo da. Discriminação múltipla e discriminação interseccional: aportes do feminismo negro e do direito da antidiscriminação. Revista Brasileira de Ciência Política, Brasília, n. 16, p. 11-37, jan./abr. 2015. p. 22-23). 
sociais (art. 3o, III), com vistas à construção de uma sociedade justa e solidária (art. 3o, I), ao mesmo tempo em que garantiu a não exclusão de quaisquer direitos ou garantias, mesmo que não expressos, desde que decorrentes do regime e dos

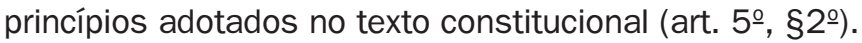

Tal centralidade do valor dignitário da pessoa humana, de superioridade constitucional no ordenamento brasileiro, acarreta a proeminência das situações existenciais e a proteção dos vulneráveis, o que descortinou o movimento de "despatrimonialização" do direito civil, outrora com forte predomínio das relações patrimoniais. ${ }^{21} \mathrm{Na}$ busca pela promoção do livre desenvolvimento da pessoa humana, as relações familiares perfazem vínculos cruciais à autorrealização e solidariedade, de modo a permitir, com especial relevância, o cumprimento dos desígnios constitucionais de tutela prioritária do sujeito concretamente considerado. A família representa, nesse viés, a comunidade intermediária e locus privilegiado de formação do ser e desenvolvimento das suas potencialidades, além de propiciar uma rede de apoio e suporte crucial para as necessidades humanas. As entidades familiares, portanto, desempenham função essencial no livre desenvolvimento da personalidade de seus membros, notadamente para as pessoas vulneráveis, que necessitam do apoio, amparo, cuidado, assistência, respeito e consideração, que se efetivam nos vínculos familiares.

Nessa linha, a instrumentalização das famílias à autorrealização individual modifica sua tradicional vocação de instituição como fim em si mesma, configurando-se, atualmente, como o grupo social intermédio hábil a proporcionar o desenvolvimento dos membros da comunidade familial. ${ }^{22} \mathrm{~A}$ concepção instrumental das entidades familiares é fundamental para compreender as dinâmicas peculiares de cada formação a partir das suas diferenças e de acordo com as necessidades de seus integrantes. Assim, a partir de uma visão democrática das famílias, persegue-se o ideal da igualdade e da liberdade com a diminuição do discurso autoritário e patriarcal e, por conseguinte, emerge a valorização da socioafetivida$\mathrm{de}^{23}$ e do cuidado. ${ }^{24}$ Desse modo, a ideia de família-instrumento serve como chave de leitura para definir os contornos da proteção de cada entidade familiar que deve

21 PERLINGIERI, Pietro. Direito civil na legalidade constitucional. Tradução de Maria Cristina De Cicco. Rio de Janeiro: Renovar, 2008. p. 57-58.

22 MORAES, Maria Celina Bodin de. A família democrática. In: MORAES, Maria Celina Bodin de. Na medida da pessoa humana: estudos de direito civil-constitucional. Rio de Janeiro: Renovar, 2010. p. 207-234.

23 Sobre o assunto, cf. CALDERON, Ricardo Lucas. Princípio da afetividade no direito de família. Rio de Janeiro: Renovar, 2013.

24 Cf., por todos, BARBOZA, Heloisa Helena. Perfil jurídico do cuidado e da afetividade nas relações familiares. In: PEREIRA, Tânia da Silva; OLIVEIRA, Guilherme de; COLTRO, Antônio Carlos Mathias (Org.). Cuidado e afetividade. Projeto Brasil/Portugal - 2016-2017. São Paulo: Atlas, 2016. p. 175-191. 
ser guiada com base na solidariedade familiar, a partir das vulnerabilidades que identificam cada arranjo e singularizam seus integrantes.

O direito das famílias contemporâneo vive momento pendular ao transitar por dois valores constitucionais de igual patamar hierárquico. Se, por um lado, deve-se assegurar a liberdade nas escolhas existenciais que propiciem o desenvolvimento pleno da personalidade de cada pessoa integrante da família, por outro, a tutela das vulnerabilidades é imprescindível para que as relações familiares se desenvolvam em ambiente de igualdade de direitos e deveres, ${ }^{25}$ harmônico e de proteção contra qualquer forma de violência. Dessa forma, o princípio da dignidade e da solidariedade familiar ampara o dever de cuidado como instrumento necessário para a tutela das vulnerabilidades no cenário democrático das famílias, em que se torna legítima a interferência do Estado para coibir os abusos e as violências intrafamiliares e promover a proteção dos arranjos mais vulneráveis.

A doutrina salienta a necessidade de conectar o direito das famílias ao cuidado, ${ }^{26}$ como uma legítima preocupação em busca da efetiva democratização dessas relações. Nesse passo, invoca-se a "ética do cuidado" como premissa para a compreensão de que, na realidade,

somos ignorantes, vulneráveis e pessoas interdependentes e que nossa força não vem da nossa autonomia, mas da nossa relação com os outros, concluindo que os direitos de família devem ser estendidos para as relações de cuidado, que são aquelas que devem ser promovidas. ${ }^{27}$

O cuidado assume, assim, verdadeira expressão humanizadora, ${ }^{28}$ pelo que

o ser humano precisa cuidar de outro ser humano para realizar a sua humanidade, para crescer no sentido ético do termo. Da mesma maneira, o ser humano precisa ser cuidado para atingir sua plenitude, para que possa superar obstáculos e dificuldades da vida humana. ${ }^{29}$

25 TEPEDINO, Gustavo. O conceito de família entre autonomia existencial e tutela de vulnerabilidades. Tribuna do Advogado, ano LXV, n. 555, fev. 2016. Disponível em: https://www.oabrj.org.br/tribuna/ordem-age-garantirtributacao-menor-advogados/conceito-fam-ilia-entre-autonomia-existencial. Acesso em: 28 maio 2020.

26 NEVARES, Ana Luiza Maia. Uma releitura do direito real de habitação na sucessão hereditária. Migalhas, 25 jun. 2020. Disponível em: https://www.migalhas.com.br/coluna/migalhas-patrimoniais/329579/umareleitura-do-direito-real-de-habitacao-na-sucessao-hereditaria. Acesso em: 3 jul. 2020.

27 NEVARES, Ana Luiza Maia. Uma releitura do direito real de habitação na sucessão hereditária. Migalhas 25 jun. 2020. Disponivel em: https://www.migalhas.com.br/coluna/migalhas-patrimoniais/329579/umareleitura-do-direito-real-de-habitacao-na-sucessao-hereditaria. Acesso em: 3 jul. 2020.

28 CASTRO, Thamis Dalsenter Viveiros de. Bons costumes no direito civil brasileiro. São Paulo: Almedina, 2018. p. 213 e ss.

29 WALDROW, Vera Regina. Abrigo e alternativas de acolhimento familiar. In: PEREIRA, Tânia da Silva; OLIVEIRA, Guilherme de. O cuidado como valor jurídico. Rio de Janeiro: Forense, 2008. p. 309. 
A respeito da prole já se disse, por exemplo, que o cuidado alcança, concretamente, a qualidade de valor jurídico, ${ }^{30}$ pois, "constituindo-se o cuidado fator curial à formação da personalidade do infante, deve ele ser alçado a um patamar de relevância que mostre o impacto que tem na higidez psicológica do futuro adulto". 31

Trata-se, com efeito, de compreender o cuidado como novo paradigma jurídico a impor a criação de condições que permitam a autonomia existencial de todas as pessoas, e especialmente daquelas nas quais a vulnerabilidade demanda maior intervenção protetiva. Mas, a efetividade da tutela dos vulneráveis requer uma concepção ampliada que compreenda o cuidado como valor jurídico gerador não só de direitos, mas também de deveres, a orientar as relações entre particulares e vincular o Poder Público nas ações de proteção às pessoas e redução de suas condições de vulnerabilidade.

Dessa dimensão criadora de deveres jurídicos, depreende-se a necessidade de políticas públicas e iniciativas legislativas voltadas às peculiaridades que o cuidado atual com os vulneráveis exige, além de considerar o importante papel que o cuidado desempenha na prevenção de vulnerabilidades. De fato, é inegável a importância do cuidado para pautar a atuação do Poder Público no sentido de reduzir as causas e os efeitos da vulnerabilidade para as gerações futuras, norteando políticas e ações que tenham como objetivo a promoção de mudanças estruturais e duradouras na sociedade. ${ }^{32}$ Mas ao lado desse compromisso público com a redução futura das vulnerabilidades sociais, é preciso compreender a emergência do cuidado em épocas de crise, nas quais se exigem desse valor resultados concretos muito além do seu conteúdo programático.

30 STJ, 3a T. REsp no 1.159.242/SP. Rel. Min. Nancy Andrighi, j. 24.4.2012: “CIVIL E PROCESSUAL CIVIL. FAMÍLIA. ABANDONO AFETIVO. COMPENSAÇÃO POR DANO MORAL. POSSIBILIDADE. 1. Inexistem restrições legais à aplicação das regras concernentes à responsabilidade civil e o consequente dever de indenizar/compensar no Direito de Família. 2. O cuidado como valor jurídico objetivo está incorporado no ordenamento jurídico brasileiro não com essa expressão, mas com locuções e termos que manifestam suas diversas desinências, como se observa do art. 227 da CF/88. 3. Comprovar que a imposição legal de cuidar da prole foi descumprida implica em se reconhecer a ocorrência de ilicitude civil, sob a forma de omissão. Isso porque o non facere, que atinge um bem juridicamente tutelado, leia-se, o necessário dever de criação, educação e companhia - de cuidado - importa em vulneração da imposição legal, exsurgindo, daí, a possibilidade de se pleitear compensação por danos morais por abandono psicológico. 4. Apesar das inúmeras hipóteses que minimizam a possibilidade de pleno cuidado de um dos genitores em relação à sua prole, existe um núcleo mínimo de cuidados parentais que, para além do mero cumprimento da lei, garantam aos filhos, ao menos quanto à afetividade, condições para uma adequada formação psicológica e inserção social".

31 STJ, 3a T. REsp no 1.159.242/SP. Rel. Min. Nancy Andrighi, j. 24.4.2012.

32 Precaução e prevenção são expressões do cuidado para além do tempo presente. Como esclarece Leonardo Boff, vem desse compromisso do cuidado com as gerações futuras os princípios da precaução e da prevenção, tão caros à tutela do meio ambiente no Brasil. Cf. BOFF, Leonardo. O cuidado necessário: na vida, na saúde, na educação, na ecologia, na ética e na espiritualidade. Petrópolis: Vozes, 2012. p. 31 e ss. 
No contexto da monoparentalidade, a ausência de proteção jurídica específica revela o alto grau de negligência sofrida por essas entidades familiares no Brasil. Sem gozar de uma tutela jurídica que considere as particularidades desse tipo familiar protagonizado pela mulher e carregado das marcas da desigualdade de gênero e de raça no país, as famílias monoparentais são excluídas de ações concretas voltadas ao cuidado e à promoção da dignidade de seus membros. E os efeitos dessa invisibilidade jurídica se fazem sentir com mais força no momento da pandemia, quando o agravamento da desigualdade social amplia o quadro de necessidades e expõe a urgência de ações de cuidado dirigidas a essa grande parcela da população, como se verá a seguir.

\section{Os impactos da pandemia e a ausência de tutela efetiva para as famílias monoparentais}

Desde os primeiros registros oficiais do coronavírus (Covid-19) no Brasil, em março de 2020 , foram adotadas importantes medidas sanitárias de distanciamento e isolamento social que produziram importantes impactos sociais, econômicos e jurídicos na sociedade brasileira. A pandemia tem gerado consequências negativas em nível global, mas não há dúvidas de que a intensidade dos seus efeitos negativos é maior em países cuja sociedade já era marcada por altos níveis de desigualdade social, econômica, ambiental e de gênero. E é preciso considerar, ainda, que em cada um desses países especialmente vulneráveis aos desdobramentos negativos da pandemia haverá famílias mais suscetíveis ao agravamento da desigualdade, como é o caso da família monoparental.

Como esclarece Boaventura de Souza Santos, "qualquer quarentena é discriminatória, mais difícil para uns grupos sociais do que para outros e impossível para um vasto grupo de cuidadores, cuja missão é tornar possível a quarentena ao conjunto da população". Por isso, alguns grupos "padecem de uma especial vulnerabilidade que precede a quarentena e se agrava com ela". 0 autor designa de Sul "um espaço-tempo político, social e cultural. É a metáfora do sofrimento humano injusto causado pela exploração capitalista, pela discriminação racial e pela discriminação sexual". ${ }^{33}$ Nesse contexto, não é demasia afirmar que as famílias monoparentais femininas estão "a Sul da quarentena".

33 SANTOS, Boaventura de Souza. A cruel pedagogia do vírus. Coimbra: Almedina, 2020. Disponível em: file:///C:/Users/55219/Downloads/Livro\%20Boaventura\%20-\%20A\%20pedagogia\%20do\%20\%20virus. pdf.pdf. Acesso em: 5 maio 2020. 
Inevitável que a dinâmica das relações familiares sofresse um significativo impacto em razão das medidas de enfrentamento ao novo coronavírus, em especial por causa do isolamento social, o que gerou em alguns casos impactos na conjugalidade, em especial o aumento pela procura de divórcios, os relacionamentos virtuais e a explosão das denúncias de violência doméstica. ${ }^{34}$ Por outro lado, repercussões foram sentidas na guarda e convivência com os filhos, como nos casos de impossibilidade de convívio dos filhos com um dos genitores em casos de dificuldade de locomoção por causa das restrições ou por um dos pais ser profissional da saúde, ex-cônjuges e ex-companheiros que voltaram a dividir o mesmo teto para cuidar da prole em comum. Além, obviamente, dos efeitos econômicos no padrão de vida de alguns genitores que apresentam dificuldades para o cumprimento da pensão alimentícia judicialmente fixada. ${ }^{35}$ É certo que, por um lado, o convívio contínuo, e, por outro, o distanciamento forçado têm motivado o repensar dos comportamentos individuais e, por conseguinte, da própria estrutura familiar e seus valores. ${ }^{36} \mathrm{O}$ diálogo, o cuidado recíproco e as soluções negociadas mostram-se como as saídas mais vantajosas para todos os envolvidos e preservam os valores constitucionais da solidariedade familiar e da dignidade de todos os membros.

Mais grave, contudo, é a situação de diversas famílias monoparentais, em regra chefiadas por mulheres, profundamente afetadas pela crise provocada pela pandemia do Covid-19, que escancarou a vulnerabilidade social ${ }^{37}$ que assola majoritariamente essas entidades familiares. De todo relevante destacar que as mães

34 “A Ouvidoria Nacional de Direitos Humanos informou que as denúncias cresceram em média 14\% até abril deste ano em relação ao mesmo período do ano passado" (MUGNATTO, Sílvia. Crescem denúncias de violência doméstica durante pandemia. Câmara dos Deputados, 12 maio 2020. Disponível em: https:// www.camara.leg.br/noticias/661087-crescem-denuncias-de-violencia-domestica-durante-pandemia. Acesso em: 3 jul. 2020)

35 Nos termos do art. 15, da Lei no 14.010, de 10.6.2020, que dispõe sobre o Regime Jurídico Emergencial e Transitório das Relações Jurídicas de Direito Privado (RJET) no período da pandemia do coronavírus (Covid-19): “Até 30 de outubro de 2020, a prisão civil por dívida alimentícia, prevista no art. 528, §3ํe seguintes da Lei no 13.105, de 16 de março de 2015 (Código de Processo Civil), deverá ser cumprida exclusivamente sob a modalidade domiciliar, sem prejuízo da exigibilidade das respectivas obrigações".

36 Cf. MENEZES, Joyceane Bezerra de; AMORIM, Ana Mônica Anselmo de. Os impactos do Covid-19 no direito de família e a fratura do diálogo e da empatia. Civilistica.com, Rio de Janeiro, ano 9, n. 2, 2020 (ahead of print). Disponível em: http://civilistica.com/os-impactos-do-covid-19-no-direito-de-família/. Acesso em: 3 jul. 2020.

37 De acordo com o art. 20, §3o, inc. I, da Lei no 8.742/93, o parâmetro objetivo escolhido pelo legislador como apto a indicar a situação de vulnerabilidade social protegida pelo benefício de prestação continuada (BPC) é o critério do núcleo familiar com renda mensal equivalente ou menor que um quarto do salário-mínimo. Cabe destacar que a Lei no 13.982/20, que acresceu à Lei no 8.742/93 o art. 20-A, trouxe a possibilidade de se elevar o critério de aferição da renda familiar mensal per capita para até meio salário-mínimo para fins de concessão do BPC. In verbis: “Art. 20-A. Em razão do estado de calamidade pública reconhecido pelo Decreto Legislativo ํㅜ 6, de 20 de março de 2020, e da emergência de saúde pública de importância internacional decorrente do coronavírus (Covid-19), o critério de aferição da renda familiar mensal per capita previsto no inciso I do §3ำ do art. 20 poderá ser ampliado para até 1/2 (meio) salário-mínimo". 
solos enfrentam forte resistência na busca por uma vaga de emprego pelo fato de serem mulheres e com filhos e sofrerem os preconceitos inerentes à maternidade no Brasil. A diferença salarial ainda é gritante, bem como as dificuldades para conseguir vagas em creches e escolas ou alguém para cuidar dos seus filhos são mais um obstáculo na busca por colocação profissional. A diferença entre mulheres brancas e negras no mercado de trabalho é significativa e precisa ser levada em consideração e devidamente repreendida pelo direito. ${ }^{38}$ Por isso, não raras vezes, a informalidade acaba sendo a única saída para essas mulheres. Tais fatores só aprofundam ainda mais a vulnerabilidade em perspectiva social da monoparentalidade feminina em tempos do Covid-19.

Diante de tal cenário, a Medida Provisória no 937 abriu crédito extraordinário, em favor do Ministério da Cidadania, para o auxílio emergencial de proteção social a pessoas em situação de vulnerabilidade, devido à pandemia do Covid-19, que foi instituído pela Lei no 13.982, de 2.4.2020, que alterou a Lei no 8.742 , de 7.12.1993, para dispor sobre parâmetros adicionais de caracterização da situação de vulnerabilidade social para fins de elegibilidade ao benefício de prestação continuada (BPC), e estabelece medidas excepcionais de proteção social a serem adotadas durante o período de enfrentamento da emergência de saúde pública de importância internacional decorrente do coronavírus (Covid-19) responsável pelo surto de 2019, a que se refere a Lei no 13.979, de 6.2.2020.

Nos termos do art. 2o, em sua redação original, o auxílio emergencial seria concedido durante o período de 3 (três) meses no valor de $\mathrm{R} \$ 600,00$ (seiscentos reais) mensais ao trabalhador que cumulativamente cumprisse os requisitos da maioridade civil e não tivesse emprego formal ativo. Em seus $\S \S 1^{\circ}$ e e $2^{\circ}$, o legislador limitou o recebimento do auxílio emergencial a 2 (dois) membros da mesma família e a substituição do benefício do Bolsa Família em auxílio emergencial nas situações em que fosse mais vantajoso. Em realce, salutar medida foi prevista no $\S 3$ o ao prever que a mulher provedora de família monoparental receberia 2 (duas) cotas do auxílio. Apesar da inovadora menção à família monoparental em sede infraconstitucional, a exclusão das mães adolescentes e dos homens que exercem solitariamente a função parental logo chamou atenção e mereceram críticas. A primeira se refere à maternidade precoce no Brasil, um fenômeno, infelizmente, ainda comum no Brasil e que é causa já tradicional da monoparentalidade feminina e acarreta a convivência com a família nuclear da mãe e, não raras vezes, na mesma unidade domiciliar dos avós maternos. A exigência da maioridade impedia que mães adolescentes pudessem ser beneficiárias do benefício, o que agravava

38 As mulheres negras ganham menos que homens negros, que, por sua vez, são mais mal remunerados que mulheres brancas, como apontou a já referida pesquisa do IBGE sobre desigualdade social. 
a situação de vulneração. Por força da Lei no 13.998, de 14.5.2020, o inc. I teve sua redação modificada. Vigora, atualmente, a seguinte redação: "seja maior de 18 (dezoito) anos de idade, salvo no caso de mães adolescentes". 0 aperfeiçoamento da norma com a ampliação do benefício às mães adolescentes sem emprego formal ativo foi uma medida extremamente positiva diante da realidade brasileira.

Por outro lado, o Projeto de Lei no 873 do Senado Federal, substitutivo ao da Câmara dos Deputados, pretendia incluir como beneficiários do auxílio emergencial as famílias monoparentais masculinas com a proposição da seguinte redação alteradora ao §3으 do art. $2^{2}$ da Lei o 13.982 : “A pessoa provedora de família monoparental receberá 2 (duas) cotas do auxílio emergencial, independentemente do sexo". A redação proposta atendia ao comando constitucional da igualdade de gêneros e, sobretudo, ao melhor interesse de crianças e adolescentes integrantes de famílias monoparentais, independentemente do gênero e da orientação sexual, no entanto, o dispositivo foi vetado pelo presidente da República. As razões do veto para ampliação do benefício para as famílias monoparentais masculinas se baseiam em suposta ofensa ao

interesse público por não se prever mecanismos de proteção às mãessolo, que se constituem a grande maioria das famílias monoparentais, em face de pleitos indevidos, e atualmente recorrentes, realizados por ex-parceiros que se autodeclaram provedores de família monoparental de forma fraudulenta, cadastram o CPF do filho, e impede, por consequência, a mulher desamparada de ter acesso ao benefício.

De fato, são notórias as fraudes no auxílio emergencial, que foram amplamente divulgados pela mídia e levaram o Tribunal de Contas da União a emitir recomendação para execução do auxílio emergencial, a fim de evitar pagamentos indevidos e exclusão do programa de pessoas que teriam direito ao benefício. Por outro lado, excluir a assistência aos filhos de formações monoparentais masculinas, que, em última análise, legitima o recebimento de 2 (duas) cotas do auxílio emergencial, não parece encontrar amparo na Constituição, tampouco no dever de solidariedade exigido pelo momento de pandemia do Covid-19. Eventuais fraudes devem ser combatidas por meio de um sistema transparente, confiável e seguro e que, definitivamente, não permita o prejuízo às mulheres que chefiam as famílias monoparentais, eis que o pai que se autodeclara fraudulentamente provedor da família sequer teria direito às duas cotas, uma vez que não se trata de família monoparental.

Os problemas do sistema de execução do auxílio emergencial não derivam somente das fraudes, mas também da própria estrutura de dados e ineficiência do 
sistema. As filas imensas em diversas agências e em diferentes cidades comprovaram tal afirmação e geraram aglomerações indevidas em tempos de pandemia. Um triste episódio demonstra bem a humilhante situação que milhares de brasileiros vulneráveis vivenciam. Roseli Vaz, grávida de sete meses e em gestação de risco, esperou durante 14 (catorze) horas na porta de uma agência da Receita Federal em Madureira, na zona norte do Rio de Janeiro, para ser atendida e conseguir regularizar o seu CPF e ter acesso ao auxílio emergencial para alimentar suas outras duas filhas e a que está por nascer. ${ }^{39}$

Nas últimas décadas, a legislação brasileira tem, finalmente, compreendido o papel da mulher nos arranjos familiares e sua atuação como provedora e todos os ônus em relação aos cuidados com o filho, em especial nos casos de monoparentalidade em razão do divórcio, separação e dissolução da união estável, que, em muitos casos, se revelam como abandono e desamparo ao invés de mero término da relação de conjugalidade por questões afetivas. Bom exemplo é a Lei ํo 11.977, de 7.7.2009, que dispõe sobre o Programa Minha Casa, Minha Vida - PMCMV e a regularização fundiária de assentamentos urbanos, posteriormente modificada pela Lei oㅡ 12.424/2011, e que expressamente reconhece a prioridade de atendimento às famílias com mulheres responsáveis pela unidade familiar como beneficiárias do PMCMV, nos termos do art. 3o, inc. IV. 0 art. 35 ainda estabelece que os contratos e registros no âmbito do PMCVM serão formalizados, preferencialmente, em nome da mulher.

A Lei o 12.693/2012 incluiu mais dois dispositivos à Lei o 11.977/2009, que privilegiam a mulher nos casos de separação, divórcio ou dissolução da união estável e afastam a necessidade de outorga conjugal seja para registro do título de propriedade ou sua transferência de imóveis adquiridos na constância do casamento ou união estável, independentemente do regime de bens escolhido pelo casal, com subvenções oriundas de recursos do orçamento público, ${ }^{40}$ bem como afasta a necessidade de outorga conjugal nos contratos em que a beneficiária

39 DONDOSSOLA, Edivaldo. 'Humilhante', diz grávida após passar a noite em fila de agência da Receita Federal no Rio. G1, Rio de Janeiro, 22 abr. 2020. Disponível em: https://g1.globo.com/rj/rio-de-janeiro/ noticia/2020/04/22/humilhante-diz-gravida-apos-passar-a-noite-em-fila-de-agencia-da-receita-federal-no-rio. ghtml. Acesso em: 4 jun. 2020. Caso extraído da leitura de PETRONE, Talíria. (Re)nascer em tempos de pandemia: uma carta à Moana Mayalú. São Paulo: Boitempo, 2020. Edição do Kindle. “Outro dia, o jornal mostrou a história de uma mulher gestante que passou a noite dormindo na fila em frente a uma unidade de atendimento da Receita Federal para regularizar seus documentos e ter acesso a um auxílio emergencial dinheiro que o governo federal disponibilizou para famílias vulneráveis durante a pandemia do coronavírus".

40 "Art. 35-A que estabelece que nas "hipóteses de dissolução de união estável, separação ou divórcio, o título de propriedade do imóvel adquirido no âmbito do PMCMV, na constância do casamento ou da união estável, com subvenções oriundas de recursos do orçamento geral da União, do FAR e do FDS, será registrado em nome da mulher ou a ela transferido, independentemente do regime de bens aplicável, excetuados os casos que envolvam recursos do FGTS". 
seja mulher chefe de família, ${ }^{41}$ nos termos dos arts. 35-A e 73-A, ressalvados os casos que envolvam o uso de recursos do FGTS do cônjuge. Tais dispositivos atendem ao comando da isonomia substancial, especialmente porque as mulheres, em termos estatísticos, são as mais oneradas com o cuidado, a criação e o sustento dos filhos, como já reiterado. Portanto, não se visualiza nenhuma inconstitucionalidade em relação ao comando legal de preferência da mulher como beneficiária destes programas de assistência.

Outro bom exemplo, anterior ao PMCMV, é a Lei no 10.836, de 9.1.2004, que criou o Programa Bolsa Família e que, em seu art. 2o, §14 estabelece que o "pagamento dos benefícios previstos nesta Lei será feito preferencialmente à mulher, na forma do regulamento". O Programa Bolsa Família é o resultado da unificação das ações de transferência de renda para a população vulnerável em âmbito federal, cuja implementação articula as políticas de saúde, educação e assistência social e conjuga esforços de estados e municípios. Por meio das informações do Cadastro Único, que foi criado em 2001 como instrumento de identificação das famílias brasileiras de baixa renda e utilizado para seleção de beneficiários de programas federais voltados para esse público, é possível traçar um perfil socioeconômico dos beneficiários do Bolsa Família. De acordo com dados de 2013, em relação aos arranjos familiares dos beneficiários do programa, a maior parte é de famílias monoparentais femininas (42,2\%), seguida por casais com filhos (37,6\%), o que denota um "incremento na participação de mulheres com filhos e sem cônjuge entre as famílias brasileiras, em especial entre as famílias de baixa renda". ${ }^{42}$

Cabe mencionar ainda a dicção do art. 1.240-A, incluído no Código Civil por meio da Lei no 12.424/2011, que estabelece:

Aquele que exercer, por 2 (dois) anos ininterruptamente e sem oposição, posse direta, com exclusividade, sobre imóvel urbano de até 250m2 (duzentos e cinquenta metros quadrados) cuja propriedade divida com ex-cônjuge ou ex-companheiro que abandonou o lar, utilizando-o para sua moradia ou de sua família, adquirir-lhe-á

41 “Art. 73-A. Excetuados os casos que envolvam recursos do FGTS, os contratos em que o beneficiário final seja mulher chefe de família, no âmbito do PMCMV ou em programas de regularização fundiária de interesse social promovidos pela União, Estados, Distrito Federal ou Municípios, poderão ser firmados independentemente da outorga do cônjuge, afastada a aplicação do disposto nos arts. 1.647 a 1.649 da Lei no 10.406, de 10 de janeiro de 2002 (Código Civil)".

42 CAMARGO, Camila Fracaro; CURRALERO, Claudia Regina Baddini; LICIO, Elaine Cristina; MOSTAFA, Joana. Perfil socioeconômico dos beneficiários do Programa Bolsa Família: o que o Cadastro Único Revela? In: CAMPELLO, Tereza; NERI, Marcelo Côrtes. Programa Bolsa Família: uma década de inclusão e cidadania. Brasília, Ipea, 2013. p. 157-177, capítulo 9. Disponível em: http://www.ipea.gov.br/portal/images/ stories/PDFs/livros/livros/livro_bolsafamilia_10anos.pdf. Acesso em: 4 jun. 2020. 
o domínio integral, desde que não seja proprietário de outro imóvel urbano ou rural. ${ }^{43}$

Tal dispositivo inseriu a chamada usucapião familiar ou conjugal no extenso rol de modalidades de aquisição originária de propriedade. ${ }^{44}$ Embora doutrina autorizada saliente que nada impede que "a usucapião prevista no art. 1.240-A possa, eventualmente, beneficiar ex-compossuidores do sexo masculino, no curso do século XXI, em muitos lares do país, dentro ou fora do perímetro urbano, o "homem da casa" será a mulher". ${ }^{45}$ Tem-se, assim, mais um instrumento que serve de proteção para as famílias monoparentais brasileiras, na maior parte dos casos, chefiadas por mulheres sobrecarregadas com as atividades domésticas e os cuidados exclusivos dos filhos.

\section{Considerações finais}

Com a pandemia do Covid-19 e as medidas de isolamento social que tiveram de grande impacto na economia brasileira, tornou-se ainda mais evidente a importância de uma disciplina jurídica específica para a proteção da família monoparental, especialmente em razão da forte vulnerabilidade social que atinge essa formação familiar. Caracterizada por uma estrutura que onera somente um ascendente no cuidado, criação e sustento integral com seus filhos, a maioria das famílias monoparentais brasileiras é liderada por mulheres e o recorte de raça vulnera ainda mais as famílias monoparentais femininas negras.

Como os dados estatísticos revelam, esses arranjos familiares precisam de proteção reforçada no âmbito social em razão dos rendimentos inferiores e da sobrecarga de trabalho de um dos genitores, em regra, da mãe, na assistência aos filhos. Embora não seja somente na dimensão econômica que as famílias monoparentais sejam afetadas pela pandemia, no período pandêmico a questão patrimonial se torna especialmente preocupante diante das dificuldades de custeio das despesas básicas com saúde, habitação e alimentação dessas famílias

43 Convém destacar o Enunciado no 595 do Conselho da Justiça Federal: “O requisito 'abandono do lar' deve ser interpretado na ótica do instituto da usucapião familiar como abandono voluntário da posse do imóvel somado à ausência da tutela da família, não importando em averiguação da culpa pelo fim do casamento ou união estável".

44 Cf. GAMA, Guilherme Calmon Nogueira; MARÇAL, Thaís Boia. Aspectos polêmicos da “usucapião conjugal": questões afetas ao art. 1.240-A do Código Civil brasileiro. Revista de Direito Privado, São Paulo, v. 54, p. 257-277, abr./jun. 2013.

45 MAIA, Roberta Mauro Medina. Usucapião familiar, composse e condomínio: um cotejo necessário. Migalhas, 23 abr. 2020. Disponivel em: https://www.migalhas.com.br/coluna/migalhas-patrimoniais/325207/usu capiao-familiar-composse-e-condominio-um-cotejo-necessario. Acesso em: 4 jun. 2020. 
compostas por vulneráveis que demandam diferentes graus de atenção e cuidado, como crianças, idosos e pessoas com deficiência.

Como consequência do dever jurídico de cuidado, das diretrizes constitucionais de proteção da dignidade e da solidariedade social e da proteção integral de crianças e adolescentes, é urgente ampliar a reflexão sobre a vulnerabilidade social das famílias monoparentais e avançar para ações efetivas do Poder Público, por meio de políticas públicas, como proteção social suplementar, benefícios sociais e deduções fiscais, a partir de cada realidade e com rígidos critérios de controle e fiscalização. É preciso construir novos instrumentos jurídicos no âmbito do direito das famílias para reequilibrar as responsabilidades parentais, tutelar as demandas da monoparentalidade em uma perspectiva efetivamente crítica e promover e garantir a igualdade substancial entre as entidades familiares.

Informação bibliográfica deste texto, conforme a NBR 6023:2018 da Associação Brasileira de Normas Técnicas (ABNT)

CASTRO, Thamis Dalsenter Viveiros de; ALMEIDA, Vitor. Famílias monoparentais, vulnerabilidade social e cuidado. Revista Brasileira de Direito Civil - RBDCivil, Belo Horizonte, v. 28, p. 77-96, abr./jun. 2021.

Recebido em: 07.06.2020

1ํ parecer em: 13.04.2021

2o parecer em: 06.05. 2021 